\title{
monumento a la mano abierta
}

LE CORBUSIER, arquitecto

$184 \cdot 7$

Chandigarh es ya la nueva capital del Pundjab.

Ha sido proyectada por un equipo capitaneado por Le Corbusier. Se ha trabajado de corazón, animados todos sus componentes por un alto espíritu, con entusiasmo.

$\mathrm{Su}$ labor de equipo no se ha visto entorpecida por las fuertes individualidades que lo integran: al contrario. La labor era inmensa y se centraba en el Capitol, corazón principal de la nueva ciudad y cabeza del nuevo Estado. En el Capitol se dispusieron los edificios alrededor de un gran parque: la Asamblea, el Palacio de los Ministerios, Palacio del Gobernador, Palacio de Justicia o Tribunal Supremo. En el parque se construyeron estanques y el gran lago artificial, uno de cuyos lindes, la Avenida del Agua, corre a lo largo del muro de contención de $4 \mathrm{~km}$ de longitud que lo creó, cortando uno de los ríos que atraviesan los terrenos en que se construye la ciudad. Este lago se proyectó para-en lo posible-suavizar el clima heroico y aplastante en los meses más duros.

En el centro del conjunto se excavó en el terreno un amplio anfiteatro para asambleas públicas, en el cual se colocará el monumento a la Mano Abierta, símbolo de la postura espiritual del Pundjab.

La India encierra tesoros de civilización; en ella todo está informado por una alta filosofía religiosa. Le Corbusier inició el proyecto del monumento, al parecer, meditando sobre su simbolismo.

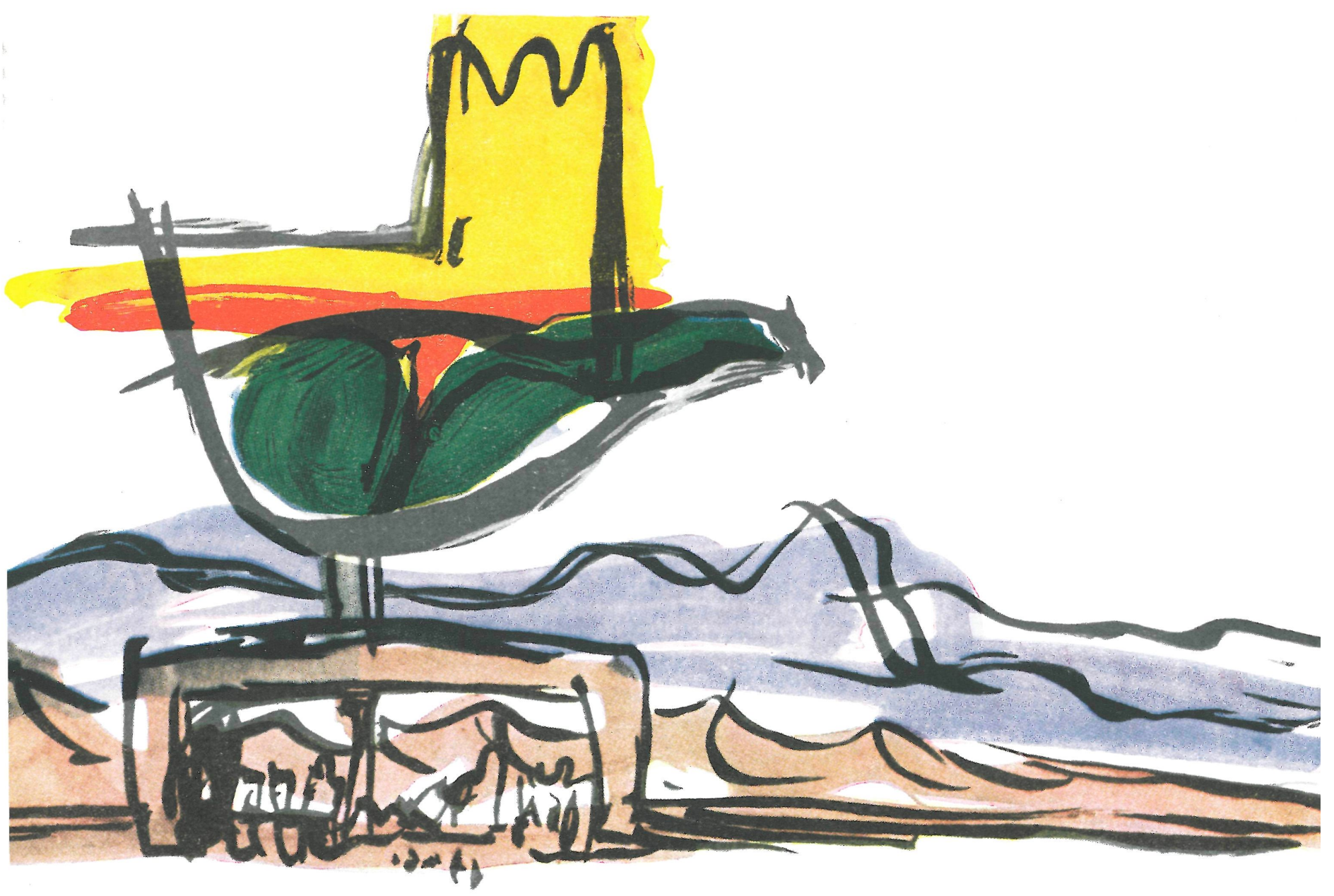


¿Cómo expresar todas las ideas que encierran las palabras: "El hombre herCien? tual del Pundjab donde el bolsillo está vacío.

Ya con la idea concreta traź́ croquis del monumento. Un paso más e hizo un primer modelo de barro.

$Y$ el modelo y el croquis hablaron a sus ojos de artista con dos lenguajes distintos, sombra el uno del otro, lenguajes idénticos y contrarios, confundidos y antagónicos. Le Corbusier aunó lo que de bueno en uno y otro vió, y construyó, una nueva frase síntesis de las dos precedentes, el boceto base para el monumento definitivo. Asi quedo fijada en sus infinitos perfiles "La Mano Abierta». dadas unas a plas y esmaltadas en das naranja blanco ezul pólido y code por los procedimientos indios tradi cionales, girará alrededor sueje-un vástago de hierro-sobre un rodamiento bolas, irguiéndose sobre un pedestal prismático y dominando el foso de las Asambleas.

Cerca de ella se alzarán dos estatuas: una a Gandhi, cabeza creadora y rectora de la nueva India; otra al Pandit Nehru, el hombre iniciador y conductor del nuevo Pundjab, promotor de la nueva ciudad y de cuanto encierra.
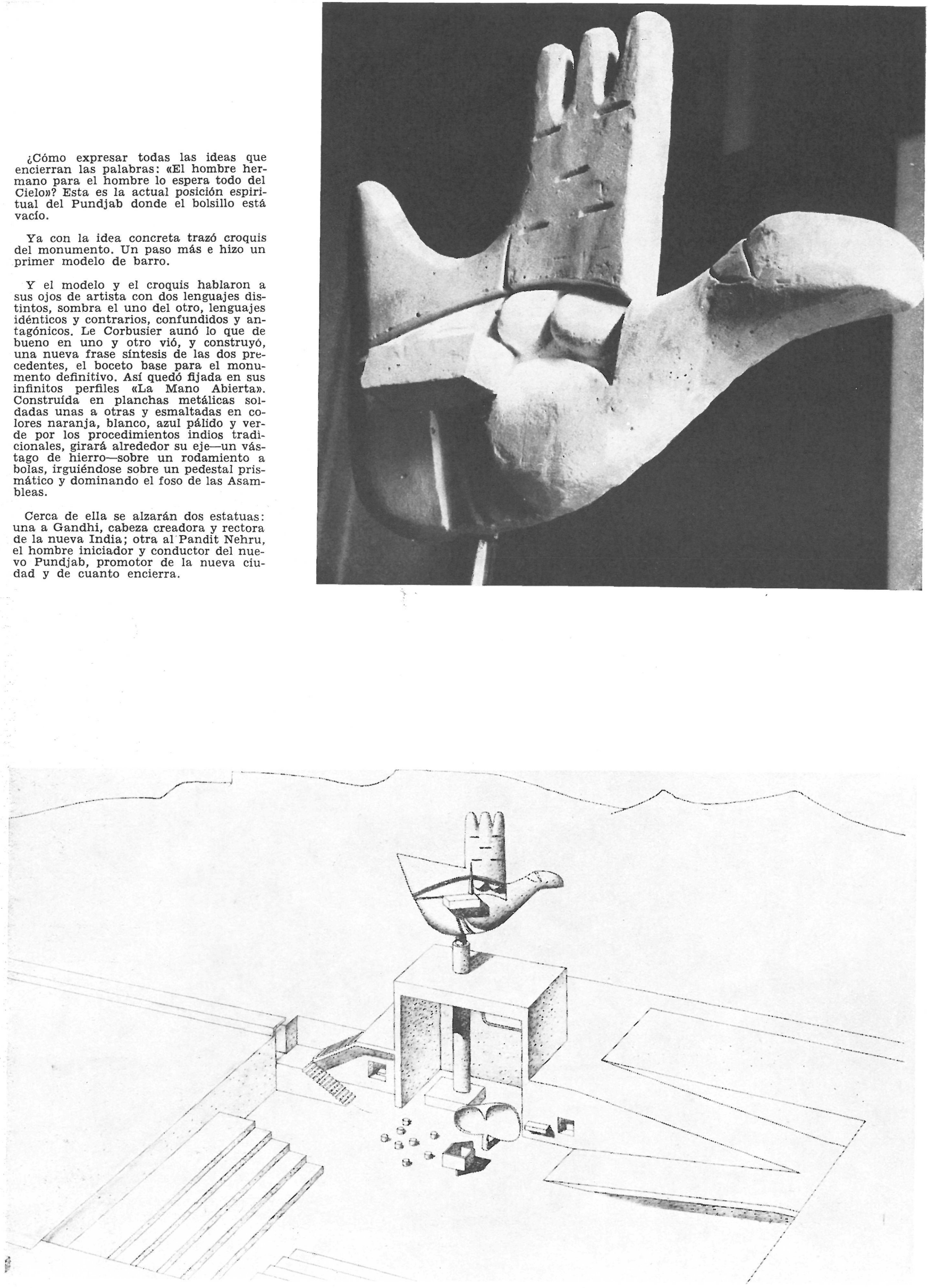

Fotos: LUCIEN HERVÉ 